\title{
The Effect of Electron Beam Irradiation on Chemical and Morphological Properties of Hansan Ramie Fibers
}

\author{
Jung Soon Lee ${ }^{\dagger}$ \\ Dept. of Clothing and Textiles, Chungnam National University; Daejeon, Korea
}

\begin{abstract}
The purpose of this study investigates the effects of electron beam(EB) irradiation on the chemical and morphological properties of Hansan ramie fiber. Hansan ramie fibers were irradiated with electron beam doses of $0,1,3,5$ and $10 \mathrm{kGy}$. The effect of electron beam irradiation on the chemical components of fibers as well as the surface chemical and morphological properties were investigated using chemical component analysis methods based on TAPPI standards, XPS, and SEM. The results indicate that the surface layers can be removed under suitable EB irradiation doses. Alcoholbenzene extraction and lignin content increases gradually with an increase in EB irradiation and reaching a maximum at an EB dose of 3kGy, and decreases at 10kGy. The surface chemical changes measured by XPS corresponded to the chemical composition analysis results. The $\mathrm{C} 1$ peak and the $\mathrm{O} / \mathrm{C}$ ratio decreased with the removal of the multi-layer and primary layer by EB irradiation. The SEM images show the inter-fibrillar structure etched by EB irradiation up to $5 \mathrm{kGy}$. At $10 \mathrm{kGy}$, the surface structure of the ramie fiber shows highly aligned and distinctive striations in a longitudinal direction. The removal of these exterior layers of the fiber was confirmed by changes in surface morphology as observed in SEM images.
\end{abstract}

Key words: electron beam irradiation, Hansan ramie, chemical composition, surface chemical property, morphological property

\section{Introduction}

An increase in environmental awareness and the number of environmental regulations has augmented interest in energy-saving and environmentally friendly materials(Na \& Kim, 2012). Composites reinforced with glass or carbon fibers, widely used in the past, have the problem of disposal after their lifetime. In modern polymer technology, a high demand exists for eco-friendly materials. Due to their biodegradable and energy saving properties, biocomposites, made of cellulosic fibers and biodegradable polymers, have recently been applied in extensive studies(Mohanty et al., 2000). Cellulosic fibers have many advantages, including low cost, low density, high strength, and biodegradability. Of these cellulosic fibers, the ramie fiber has good elasticity and specific strength and is commercially available(Hong \& Ryu, 1997). Despite these advantages, biocomposites reinforced with cellulosic fibers are not yet widely used as a result of their handicaps, including poor bonding between the cellulosic fiber and the polymer matrix due to the presence of hydroxyl and carboxylic groups and strength reduction of the reinforcement due to the low moisture resistance of cellulosic fibers (Aranberri-Askargorata et al., 2003). Adhesion between

†Corresponding author; Jung Soon Lee

Tel. +82-42-821-6830, Fax. +82-42-821-8887

E-mail: jungsoon@cnu.ac.kr the reinforcing fibers and the polymer matrix plays an important role because external stimulation transfer between the matrix and fibers determines the final mechanical properties and reinforcement efficiency. To overcome the drawbacks of cellulose fibers, plasma treatment(Lee et al., 2003; Yuan et al., 2004), ultra-violet irradiation(Halina \& Dagmara, 2006; Khan et al., 2006) and electron beam(EB) irradiation have been successfully employed to produce significant physical and chemical changes, as well as changes in the surface structures and surface energies of the fibers. These methods are simple and lead to the formation of functional groups in the hydrophobic polymer chains, resulting in the molecular cross-linking of the cellulose fiber and polymer(Halina et al., 2005; Iller et al., 2002).

The EB irradiation technique is being increasingly utilized to modify the surfaces of various polymer materials, such as fibers, wires, and films. Han et al.(2006) reported EB irradiation is effective in achieving both impurity removal and functional group development on the surface of natural fibers for better bonding with the polymer matrix(Han et al., 2006). Han et al.(2007) also studied cellulose degradation caused by EB irradiation by investigating its viscosity(Han et al., 2007). Dehydrogenation and destruction of an hydroglucose was found to occur on the cellulose surface at a high irradiation dose while at a low irradiation dose, the cellulose may undergo cross-linking(Takacs et al., 1999).

The effects of EB irradiation on the surface of cellulosic fiber 
can be explained using two different approaches. One is to investigate the surface morphology using scanning electron microscopy(SEM) and atomic force microscopy(AFM) and the other is to investigate the chemical characteristics of fiber surface using X-ray photoelectron spectroscopy(XPS), and Fourier transform infrared(FTIR) spectroscopy for chemical analysis(Koljonen et al., 2003; Oh et al., 2005). A combination of chemical and morphological information should yield better insight into the complex and functionally designed cellulose fiber surfaces.

The present study was undertaken with the aim of elucidating the chemical and morphological surface changes induced by EB irradiation of ramie fibers using chemical component analysis, XPS, and SEM. The surface chemical changes were compared to the chemical components, which were analyzed according to TAPPI standards for alcohol-benzene soluble extraction and sulfuric acidinsoluble lignin, holocellulose and $\alpha, \beta$-cellulose extraction with alkaline solution. The relationship between the chemical components or the surface chemical property and the complex structure was investigated using EB irradiation effects. The chemical and morphological studies of fibers by EB irradiation could provide vital information on the level of interfacial adhesion that would exist between the fiber and polymer matrix of biocomposite.

\section{Experimental}

\subsection{Materials}

Ramie(Boehmeria nivea) fibers from Hansan Ramie, Co., Korea were used in their natural condition. The average density was about $1.5 \mathrm{~g} / \mathrm{cm}^{3}$, and the filament diameter was generally in the range of 20-30 $\mu \mathrm{m}$. Prior to each experiment, the ramie fibers were soaked in $20^{\circ} \mathrm{C}$ distilled water for $1 \mathrm{~h}$ and washed several times to remove the cold water-soluble impurities. The fibers were then dried in an oven at $105 \pm 1^{\circ} \mathrm{C}$ for $24 \mathrm{~h}$.

\subsection{EB irradiation}

Ramie fibers were placed in a polyethylene bag and irradiated by an electron beam. The accelerator ELV-4 from eb-TECH Co. Ltd.(Daejeon, Korea) provided energy of $1.0 \mathrm{MeV}$. The beam current was $1.8 \mathrm{~mA}$ and the beam had a transport velocity of $25 \mathrm{~m} /$ $\min$. The dimensions of the beam extraction window were $980 \times$ $980 \mathrm{~mm}$. Electron beam irradiation doses of 1, 3, 5, and 10 were implemented, and a raw sample was used as a standard for comparison.

\subsection{Chemical composition analysis}

A standardized sampling procedure is provided in TAPPI Standard T257 cm-02, 2002. Ramie fibers were milled and used as

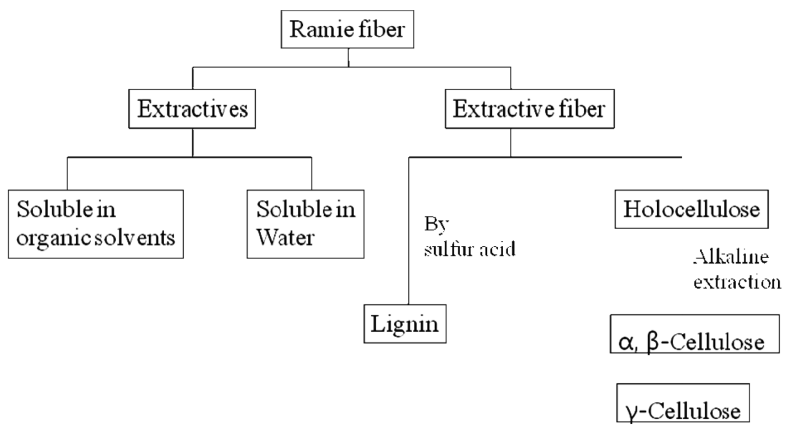

Fig. 1. The chemical composition analysis processes.

samples, which were larger than 40 mesh and smaller than 60 mesh. The procedure for chemical analysis of ramie fibers was conducted in accordance with TAPPI T264 cm-97, 1997. To prepare a sample for lignin and cellulose analysis, ethanol-benzene soluble extractives were investigated and removed by soaking in a solvent for $6 \mathrm{~h}$ to remove the extra waxes, fats, and alcohol-soluble resins. After extraction with ethanol-benzene, the holocellulose, $\alpha$ and $\beta$-celluloses, and lignin contents were measured from the extractive-free fiber according to the scheme in Fig. 1. The contents of $\alpha$ and $\beta$-celluloses and lignin were determined through triplicate performance of methods TAPPI $203 \mathrm{~cm}-99$ and T222 cm-02, 2002, and the average was recorded.

\subsection{Surface chemical property by XPS analysis}

XPS analysis was used to determine the surface chemical composition changes of the ramie fibers after EB irradiation. XPS measurements were performed with a Thermo MultiLab 2000 electron spectrometer using a monochromated $\mathrm{Al} \mathrm{K} \alpha$ source operated at $300 \mathrm{~W}$. Survey scans were taken with a $1.0 \mathrm{eV}$ step and a $50 \mathrm{eV}$ analyzer pass energy, while the high resolution regional spectra were recorded at a $0.1 \mathrm{eV}$ step and a $20 \mathrm{eV}$ pass energy. Measurements were taken at three different spots on each sample in order to calculate an average of the heterogeneous surfaces.

\subsection{Scanning electron microscopy}

SEM(JEOL JSM-6390) was used to observe the surface morphologies of the un-irradiated ramie fibers and those irradiated at different EB doses. The acceleration voltage was $20 \mathrm{kV}$, and the samples were coated with Pt using a vacuum sputter coater.

\section{Results and Discussion}

\subsection{Chemical component analysis}

The properties of natural fibers depend on their source, nature, and storage. These properties, is turn, affect the mechanical properties of the biocomposite. The ramie fibers were composed of 
Table 1. The chemical compositions of ramie fibers irradiated with different EB doses.

\begin{tabular}{ccccccc}
\hline EB dose $(\mathrm{kGy})$ & Extract $^{\mathrm{a}}(\%)$ & SD & Lignin $^{\mathrm{b}}(\%)$ & SD & Holocellulose $^{\mathrm{c}}(\%)$ & SD \\
\hline 0 & 1.592 & \pm 0.04 & 3.743 & \pm 0.065 & 79.28 & \pm 0.695 \\
1 & 1.899 & \pm 0.02 & 3.991 & \pm 0.06 & 80.22 & \pm 0.17 \\
3 & 2.158 & \pm 0.095 & 4.505 & \pm 0.03 & 78.07 & \pm 0.48 \\
5 & 2.109 & \pm 0.06 & 4.311 & \pm 0.08 & 80.19 & \pm 0.18 \\
10 & 1.896 & \pm 0.035 & 3.08 & \pm 0.14 & 78.36 & \pm 0.29 \\
\hline
\end{tabular}

${ }^{a}$ Extract, \%: extraction with alcohol+benzene solution

${ }^{\mathrm{b}}$ Lignin, \%: Klason lignin

${ }^{c}$ Holocellulose, \%: $\alpha$-cellulose $+\beta$-cellulose $+\gamma$-cellulose

$79.28 \%$ cellulose, $3.7 \%$ lignin, and $1.6 \%$ extractions, according to the results of chemical component analysis. Cellulose forms the main component of natural cellulosic fibers and consists of $\alpha$-cellulose, $\beta$-cellulose, and $\gamma$-cellulose, which together make up holocellulose. The ramie fibers grown in Hansan, Korea, consist of $55.27 \% \alpha$-cellulose, $3.27 \% \beta$-cellulose, and $20.74 \% \gamma$-cellulose. Of all the celluloses, $\alpha$-cellulose primarily determines the tensile strength of the fiber(Belgacem et al., 1995; Nevell \& Zeronian, 1985).

Changes in the chemical component, such as alcohol-benzene extracts, lignin, and cellulose in ramie fibers at the different EB irradiation doses are shown in Table 1. It has been shown that the amount of alcohol-benzene extract increases gradually with an increase in EB irradiation and reaching a maximum at an EB dose of $3 \mathrm{kGy}$, and decreases at $10 \mathrm{kGy}$. The walls of cellulosic fiber are constructed of four distinct layers: the middle lamella(ML) and the primary, secondary, and tertiary cell walls. Fig. 2 is the scheme of the morphological architecture of ramie fiber(Klemm et al., 1998). The exterior of the layer, the ML, contains mainly impurities and alcohol-benzene extractives, such as pectin and proteinaceous material. Adjacent to the ML, the primary wall(P) layer consists of $50 \%$ cellulose, as well as lignin and extracts, such as waxy, pectinaceous, and proteinaceous materials. In the untreated fibers, the impurities are completely attached to ML and P layer of the ramie fiber(Nevell \& Zeronian, 1985). The impurities between ML and P layer were not dissolved well in the alcohol-benzene solution, which has a soluble content of $1.59 \%$. A slight increase in the alcohol-benzene soluble content was observed when the ramie fibers were irradiated, and then the impurity content decreased at $10 \mathrm{kGy}$. As shown in Table 1, the content of lignin, one of the main components of cellulose, increased slightly upon EB irradiation up to $3 \mathrm{kGy}$. However, a large decrease in lignin content was observed at $10 \mathrm{kGy}$. These changes in lignin content could also be caused by a reduction in adhesion of lignin by the low dose and the removal of the cell walls, ML, and P layer due to the EB irradiation at $10 \mathrm{kGy}$, similar to the results of the alcohol-benzene extracts. The lignin

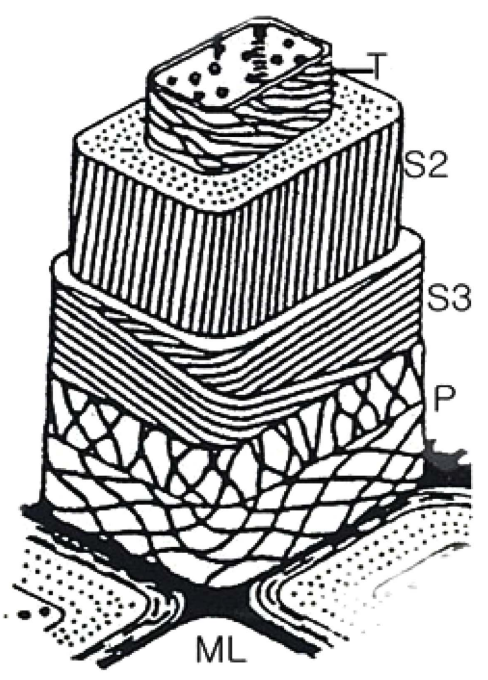

Fig. 2. Scheme of the morphological architecture of ramie fiber; MLmiddle lamella(mainly lignin), P-primary wall, S-secondary wall, Ttertiary wall. Klemm et al. (1998), p.25.

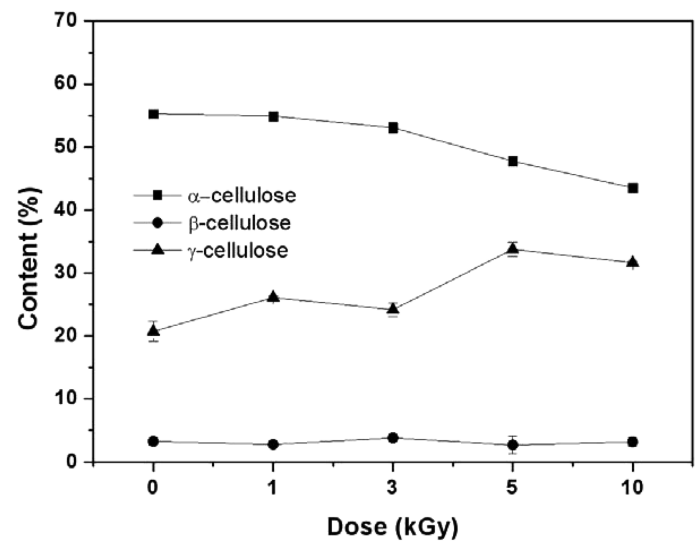

Fig. 3. The contents of $\alpha, \beta$ and $\gamma$-cellulose.

existing between the ML and $\mathrm{P}$ layer was removed with the removal of the ML and $\mathrm{P}$ layer by $\mathrm{EB}$ irradiation, leading to a decrease in the lignin content of the fibers of up to $3.08 \%$ at $10 \mathrm{kGy}$.

As seen in Table 1, no significant difference in the total holo- 
cellulose content was found as a result of EB irradiation, signifying that the cellulose component cannot be removed or transformed to another component through EB irradiation. Holocellulose consists of $\alpha$-cellulose, $\beta$-cellulose and $\gamma$-cellulose. The content of $\alpha$-cellulose was found to decrease while that of $\gamma$-cellulose increased with an increase in EB irradiation dose, as shown in Fig. 3. It means that the physical properties of fibers were transformed(Choi et al., 2009). In general, $\alpha$-cellulose indicates higher-molecularweight cellulose and $\beta$ and $\gamma$-cellulose indicates lower-molecular weight cellulose by degradation. The chain cutting of $\alpha$-cellulose by EB irradiation results in a transformation into $\gamma$-cellulose composed of minor units of cellulose polymers.

\subsection{Surface chemical analysis}

There are two alternative XPS method for lignin analysis. One is based on determination of oxygen-to carbon atomic ratios, which are different for cellulose and lignin. In the other method, the carbon high-resolution $\mathrm{C}$ 1s spectrum is deconvoluted and the lignin content is calculated from the relative concentration of the C-C component. The $\mathrm{C}-\mathrm{C}$ component in the $\mathrm{C} 1 \mathrm{~s}$ spectrum, originating from carbon atoms that have no oxygen neighbors is due to lignin only, since $\mathrm{C}-\mathrm{C}$ bonds are not present in chemically pure cellulose(Johansson, 2002).

XPS spectra were obtained for the un-irradiated and EB-irradiated ramie fibers. Cellulose is an organic compound with the formula $\left(\mathrm{C}_{6} \mathrm{H}_{10} \mathrm{O}_{5}\right)$ n composed of the elements carbon, hydrogen, and oxygen.

Table 2 summarizes the binding energies of the functional groups observed from carbon 1s spectra. The carbon 1s spectra were deconvoluted into four categories, which are shown in Fig. 4(a) and (b) are the representative spectrum of the un-irradiated and $10 \mathrm{kGy}$ irradiated ramie fiber. Four carbon bond categories were assigned: $\mathrm{C} 1$ carbons bonded to hydrogen $(\mathrm{C}-\mathrm{H}), \mathrm{C} 2$ carbons bonded to one oxygen atom $(\mathrm{C}-\mathrm{O}), \mathrm{C} 3$ carbones from carbonyl groups (O-C-O), and $\mathrm{C} 4$ carbons from carboxyl group (O-C=O) (Juan et al., 2005). The $\mathrm{C} 1$ peak corresponds to non-oxidized alkane-type carbon atoms and originates from impurities like lignin, extractive substances, and fatty acids. Some of the impurities were obtained in the alcohol-benzene solution (Belgacem et al., 1995). In the case of XPS analysis, the surface impurity content was analyzed according to the $\mathrm{C} 1$ components (Laine et al., 1994). In this study, we presume that the lignin and alcohol-benzene extract contents correspond with the $\mathrm{C} 1$ component and $\mathrm{O} / \mathrm{C}$ ratio. Table 2 shows a decrease in the $\mathrm{C} 1$ component from $3 \mathrm{kGy}$ to $10 \mathrm{kGy}$. $\mathrm{EB}$ irradiation reduced the relative amount of $\mathrm{C} 1$ and increased the relative amount of $\mathrm{C} 4$ component. This suggests that the EB irradiation reduces the lignin(Koljonen et al., 2003). These results
Table 2. The effect of fiber surface chemical modification at various EB irradiation doses in ramie fiber.

\begin{tabular}{|c|c|c|c|c|c|}
\hline \multirow{2}{*}{$\begin{array}{l}\text { EB dose } \\
(\mathrm{kGy})\end{array}$} & \multicolumn{4}{|c|}{ Peak area $(\%)$ carbon type } & \multirow[b]{2}{*}{$\mathrm{O} / \mathrm{C}$} \\
\hline & $\begin{array}{c}\mathrm{C} 1 \\
(\mathrm{C}-\mathrm{H})\end{array}$ & $\begin{array}{c}\mathrm{C} 2 \\
(\mathrm{C}-\mathrm{O})\end{array}$ & $\begin{array}{c}\mathrm{C} 3 \\
(\mathrm{O}-\mathrm{C}-\mathrm{O})\end{array}$ & $\begin{array}{c}\mathrm{C} 4 \\
(\mathrm{O}=\mathrm{C}-\mathrm{O})\end{array}$ & \\
\hline 0 & 11.78 & 68.83 & 16.06 & 3.38 & 0.317 \\
\hline 1 & 14.92 & 66 & 15.07 & 3.38 & 0.334 \\
\hline 3 & 13.79 & 66.87 & 15.11 & 4.23 & 0.432 \\
\hline 5 & 7.4 & 73.06 & 14.43 & 5.53 & 0.370 \\
\hline 10 & 6.98 & 73.71 & 14.12 & 4.77 & 0.331 \\
\hline
\end{tabular}

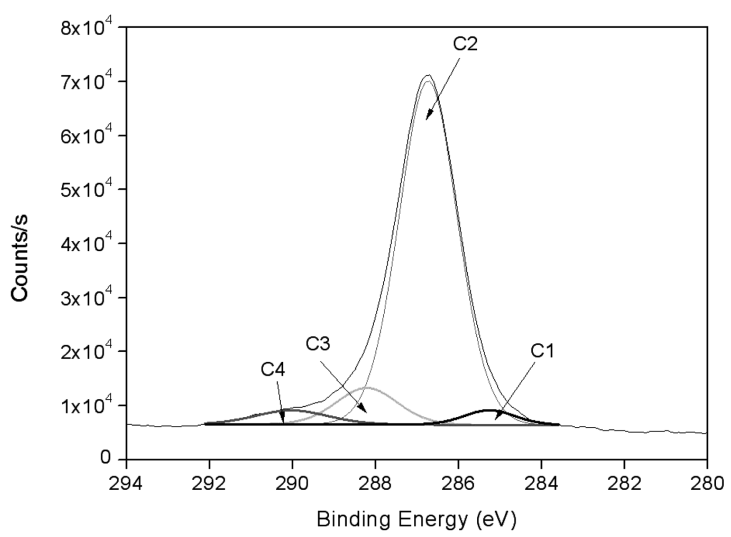

(a)

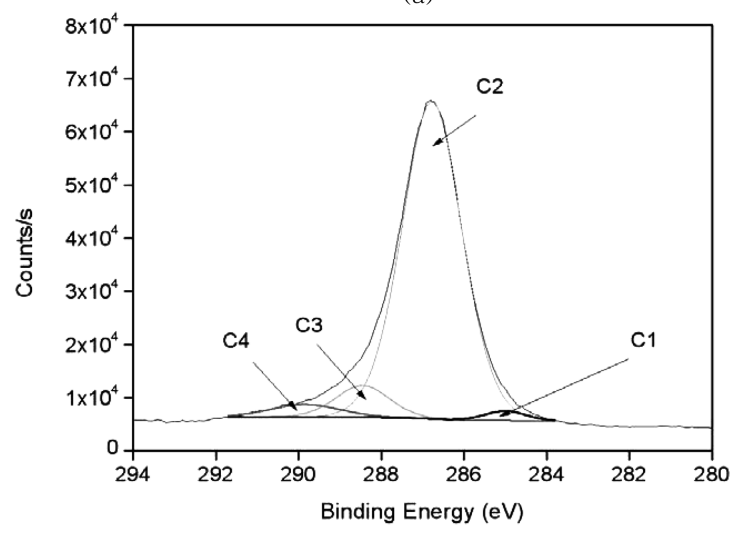

(b)

Fig. 4. High-resolution XPS spectra of the resolver carbon 1s signal for (a) an untreated ramie fiber and (b) a ramie fiber irradiated at $10 \mathrm{kGy}$.

indicate that the impurities were reduced from $3 \mathrm{kGy}$ to $10 \mathrm{kGy}$. This can be explained by the cellular structure of natural fibers. The $\mathrm{C} 1$ component decreases with the removal of the exterior layer and $\mathrm{ML}$ and $\mathrm{P}$ layer-attached impurities by EB irradiation. Choi et al.(2008) reported that the surface morphology of cellulose fiber was changed by EB irradiation resulting from the removal of pectin, waxy and $\mathrm{P}$ layer at $10 \mathrm{kGy}$.

The carbon 1s spectrum was deconvoluted to determine the relative carbon-to-oxygen content. For charge compensation, the C-C binding peak was set to a binding energy of $285 \mathrm{eV}$ to compare the 


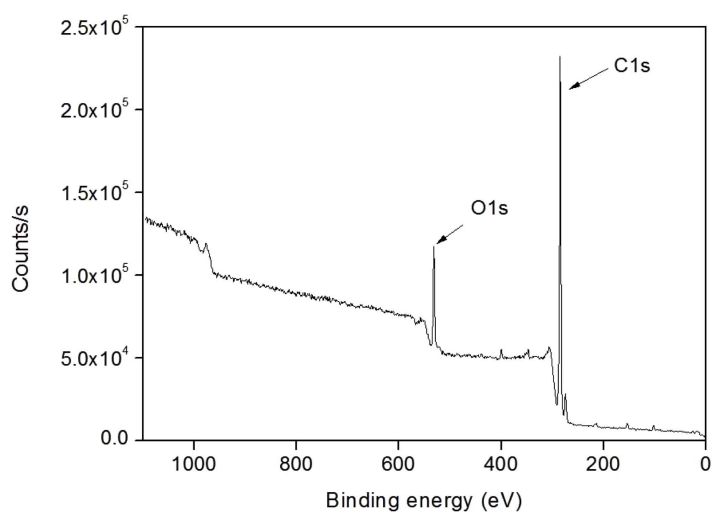

(a)

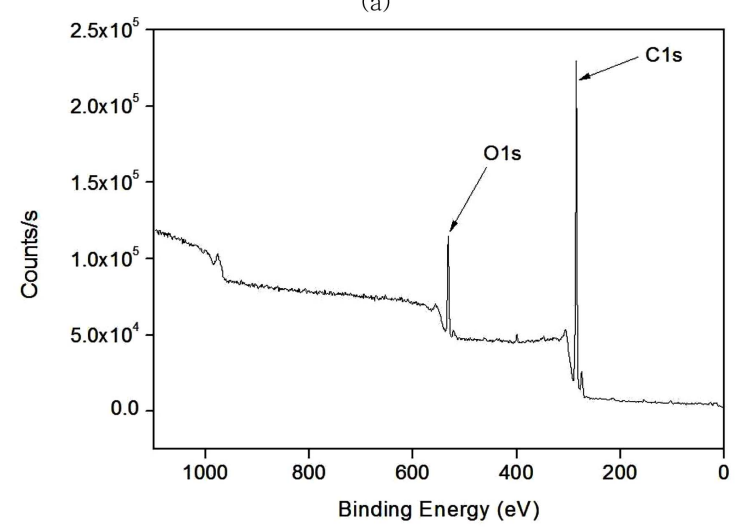

(b)

Fig. 5. Typical survey spectra and high-resolution O 1s spectra for (a) an untreated ramie fiber and (b) a ramie fiber irradiated at $10 \mathrm{kGy}$.

changes occurring in the O1s peak(Fig. 5). Table 2 also shows the atomic ratio of oxygen to carbon $(\mathrm{O} / \mathrm{C})$ on the surface of the ramie fibers irradiated with EB irradiation. Cellulose, hemicelluloses, and pectin have $\mathrm{O} / \mathrm{C}$ ratios of 0.83 , lignin has a ratio of about 0.35 , and other extracts have even lower ratios(Leena-Sisko et al., 1999). Because the $\mathrm{O} / \mathrm{C}$ ratio of ramie fiber is much lower than the expected value, less than 0.83 , the surface must have contained a greater proportion of lignin and other extracts(Sgriccia et al., 2008). As aforementioned, this was due to the exterior walls of the fiber cells. The $\mathrm{O} / \mathrm{C}$ ratio of the ramie fiber showed a maximum value at $3 \mathrm{kGy}$. This can be explained by the multi-layer structure. The secondary wall(S layer) under the $\mathrm{P}$ layer is composed of an outer S1 layer and inner S2 layer and innermost S3 layers. These three layers, the largest proportions of cellulose, are bound by lignin. From the $\mathrm{O} / \mathrm{C}$ ratio results, we presume that the $\mathrm{EB}$ irradiation removed the surface layer of the ramie fiber partly, including the ML and $\mathrm{P}$ layer. Due to the removal of the ML and $\mathrm{P}$ layer, the $\mathrm{O} / \mathrm{C}$ ratio was high at the low dose, $3 \mathrm{kGy}$. It has been shown that XPS can be used to evaluate the surface lignin content in ramie fibers irradiated with EB. Fig. 6 shows similar trends in the lignin content from the chemical component analysis and the $\mathrm{O} / \mathrm{C}$ ratio obtained from the

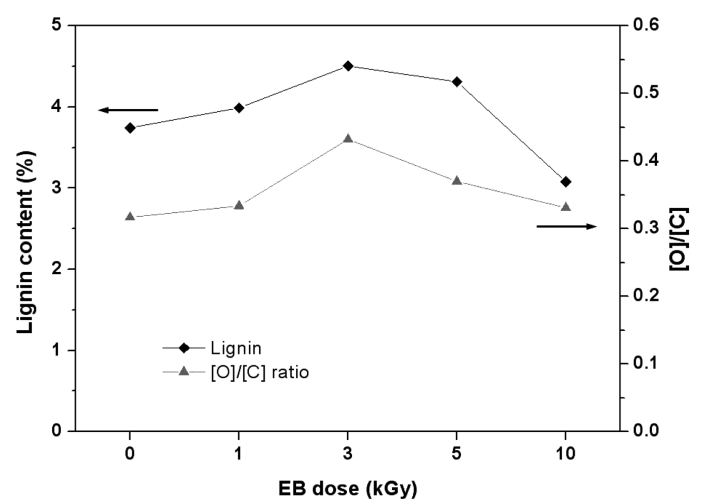

Fig. 6. Comparison between lignin content and the $\mathrm{O} / \mathrm{C}$ ratio of the fiber surface after EB irradiation at 0, 1, 3, 5, and $10 \mathrm{kGy}$.

surface chemical analysis.

\subsection{Scanning electron microscopy}

Scanning electron microscopy is an excellent technique for examining the surface morphology of fibers. It is expected that the surface morphology of the un-irradiated fiber will differ from that of the irradiated fibers, particularly in terms of roughness. Studies of fiber surface topography may provide vital information about the level of interfacial adhesion between fibers and the matrix when used later as reinforcement in a composite material. If the cellulose fiber has a rough surface, its adhesion property in the biocomposite will increase. Fig. 7 shows SEM images observed in the longitudinal directions for ramie fibers irradiated with different EB doses. The SEM image of the un-irradiated fiber shows a surface covered with weak boundary components, which act to smooth the surface. This is evidenced by the chemical analysis. The SEM images show the inter-fibrillar structure etched by EB irradiation. The ML and the P layer are located on the exterior of the fiber wall and contain abundant pectin, wax, and lignin. This is confirmed by the chemical component analysis results, which show a high concentration of alcohol-benzene extract and lignin. The XPS results also show high $\mathrm{C} 1$ components, which mean numerous impurities. At $10 \mathrm{kGy}$, the surface structure of the ramie fiber shows highly aligned and distinctive striations in a longitudinal direction. These results indicate that $\mathrm{EB}$ irradiation removes the $\mathrm{ML}$ and $\mathrm{P}$ layer and exposes the inner layer. With an increase in EB irradiation dose, the SEM images show more distinct and clearer surfaces as a result of the removal of impurities and exterior layers with irregular phases. The distinct and clear surfaces mean that the ramie fibers have a high cellulosic component. In chemical component analysis, the extract and lignin contents decreased; however, the holocellulose content did not decrease with increasing EB dose. These results indicate the removal of the ML and P layer containing impurities. 


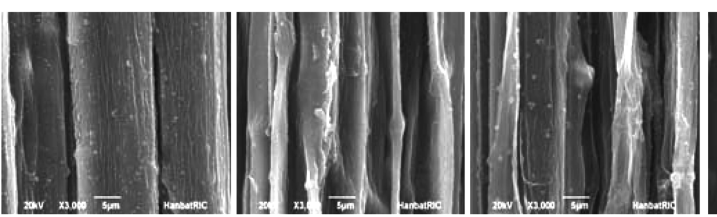

(a) (b)

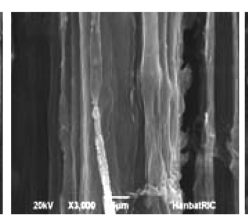

(d)

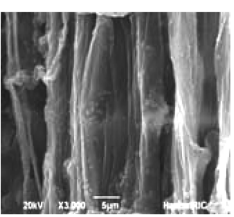

(e)

Fig. 7. SEM micrographs of ramie fibers: (a) raw ramie and ramie irradiated with (b) $1 \mathrm{kGy}$, (c) $3 \mathrm{kGy}$, (d) $5 \mathrm{kGy}$ and (e) $10 \mathrm{kGy}(\times 3000)$.

Also, XPS results showed an increase in $\mathrm{C} 1$ components, indicating impurities at higher doses. This means that the surface layer was damaged, and the lignin existing between the cellulose fibrils was exposed on the cell surface during EB irradiation.

\section{Conclusions}

This study investigated the chemical and morphological surface changes of ramie fibers induced by EB irradiation using chemical component analysis, XPS, and SEM. The results indicate that the surface of ramie fibers can be changed through EB irradiation. The chemical components and the surface chemical changes of the ramie fibers were generated by surface morphological changes.

Ramie fibers irradiated with different EB doses were analyzed using chemical component analysis and XPS. According to the chemical component analysis, with increasing irradiation doses up to $3 \mathrm{kGy}$, the extract and lignin contents increased and then decreased at doses greater than $10 \mathrm{kGy}$. These results correspond with the results of XPS at low doses of 1-10 kGy. The C1 peak and the $\mathrm{O} / \mathrm{C}$ ratio indicating lignin and extractives display a similar trend with chemical component analysis.

The surface morphology of the untreated fiber was also investigated. The SEM image of the untreated fiber shows a surface covered with weak boundary components and primarily consisting of abundant pectin, wax, and lignin. The SEM images show the interfibrillar material at low doses of EB irradiation up to $5 \mathrm{kGy}$. After irradiation with doses greater than $10 \mathrm{kGy}$, the surface structure of the ramie fiber is highly aligned, with distinctive striations in a longitudinal direction. These results indicate that $10 \mathrm{kGy}$ EB irradiation removed the ML and P layer while exposed the inner layer. The more distinct and clearer surface indicates that some of the impurities and exterior layers having irregular phases were removed with EB irradiation.

\section{Acknowledgements}

This research was supported by a Korea Research Foundation Grant funded by the Korean Government(KRF 2009-0078562).

\section{References}

Aranberri-Askargorta, I., Lampke, T., \& Bismarck, A. (2003). Wetting behavior of flax fibers as reinforcement for polypropylene. Journal of Colloid and Interface Science, 263(2), 580-589.

Belgacem, M. N., Czeremuszkin, G., Sapleha, S., \& Gandini, A. (1995). Surface characterization of cellulose fibers by XPS and inverse gas chromatography. Cellulose, 2(3), 145-157.

Choi, H. Y., Han, S. O., \& Lee, J. S. (2009). The effects of surface and pore characteristics of natural fiber on interfacial adhesion of henequen fiber/PP biocomposites. Composite Interfaces, 16(4), 359-376.

Choi, H. Y., Han, S. O., \& Lee, J. S. (2008). Surface morphological, mechanical and thermal characterization of electron beam irradiated fibers. Applied Surface Science, 255, 2466-2473.

Halina, K., \& Dagmara, O. (2006). The effect of UV-irradiation on composting of polyethylene modified by cellulose. Polymer Degraddation and Stability, 91(10), 2282-2291.

Halina, K., Dagmara, O., Przemystaw, M., \& Hanna, C. (2005). Effect of short wavelength UV-irradiation on ageing of polypropylene/ cellulosic compositions. Polymer Degradation and Stability, 88(2), 189-198.

Hong, J. M., \& Ryu, H. S. (1997). Mechanical properties and fabric handle of Hansan ramie(Part 1). Journal of the Korean Society of Clothing and Textiles, 21(8), 1315-1322.

Han, S. O., Seo, Y. B., \& Lee, C. H. (2007). Degradation of cellulosic fibers by electron beam irradiation. Journal of Korea Technical Association of the Pulp and Paper Industry, 39(5), 20-25.

Han, S. O., Cho, D., Park, W. H., \& Lawrence, D. (2006). Henequen/ poly(butylen-es succinate) biocomposites: electron beam irradiation effects on henequen fiber and the interfacial properties of biocomposites. Composite interfaces, 13(2), 231-247.

Iller, E., Kykielka, A., Stupinska, H., \& Mikolajczyk, W. (2002). Electron-beam stimulation of the reactivity of cellulose pulps for production of derivatives. Radiation Physics and Chemistry, 63(3), 253-257.

Johansson, L. (2002). Monitoring fibre surfaces with XPS in papermaking processe. Microchimica Acta, 138(3-4), 217-223.

Johansson, L. S., Campbell, J. M., Krista, K., \& Per, S. (1999). Evaluation of surface lignin on cellulose fibers with XPS. Applied Surface Science, 144-145, 92-95.

Juan, C. B., Richard, V., Joel, P., Richard, G., Stefan, Z., \& Jogn, F. K. (2005). Chemical force microscopy of cellulosic fiber. Carbohydrate Polymers, 62(4), 369-378.

Khan, M. A., Haque, N., Al-Kafi, A., Alam, M. N., \& Abedin, M. Z. (2006). Jute reinforced polymer composite by gamma radiation: effect of surface treatment with UV radiation. Polymer Plastics 
Technology and Engineering, 45(5), 607-613.

Klemm, D., Philips, B., Heinze, T., Hinze, U., \& Wagenknecht, W. (1998). Fundamentals and Analytical Methods, Volume I, Comprehensive cellulose chemistry( $1^{\text {st }}$ ed). New York: Wiley$\mathrm{VCH}$.

Koljonen, K., Osterberg, M., Johansson, L. S., \& Stenius, P. (2003). Surface chemistry and morphology of different mechanical pulps determined by ESCA and AFM. Colloids and Surfaces A: Physicochemical and Engineering Aspects, 228(1/3), 143-158.

Lee, S. G., Choi, S. S., Park, W. G., \& Cho, D. (2003). Characterization of surface modified flax fibers and their biocompoistes with PHB. Macromolecular Symposia, 197(1), 89-99.

Mohanty, A. K., Misra, M., \& Hinrichsen, G. (2000). Biofibers, biodegradable polymers and biocomposite; An overview. Macromolecular Materials and Engineering, 276/277(1), 1-24.

Na, Y. J., \& Kim, H. W. (2012). Sensibility preference of eco-friendly fabric products and trust reliability. Journal of the Korean Society for Clothing Industry, 14(3), 430-437.

Nevell, T. P., \& Zeronian, S. H. (1985). Cellulose chemistry and its applications (First ed.). New York: John Wiley \& Sons.

Oh, S. Y., Yoo, D. I., Shin, Y., Kim, H. C., Chung, Y. S., Park, W. H.,
\& Youk, J. H. (2005). Crystalline structure analysis of cellulose treated with sodium hydroxide and carbon dioxide by means of Xray diffraction and FT-IR spectroscopy. Carbohydrate Research, 340(15), 2376-2391.

Sgriccia, N., Hawley, M. C., \& Misra, M. (2008). Characterization of natural fiber surfaces and natural fiber composites. Composites: Part A., 39(10), 1632-1637.

Takacs, E., Wojnarovits, L., Borsa, J., Foldvary, C., Hargittai, P., \& Zold, O. (1999). Effect of ã-irradiation on cotton-cellulose. Radiation Physics and Chemistry, 55(5/6), 663-666.

Laine, J., Stenius, P., Carlsson, G., \& Ström, G. (1994). Surface characterization of unbleached kraft pulps by means of ESCA. Cellulose, 1(2), 145-160.

Yuan, X., Jayaraman, K., \& Bhattacharyya, D. (2004). Mechanical properties of plasma-treated sisal fibre-reinforced polypropylene composite. Journal of Adhesion Science and Technology, 18(9), 1027-1045.

(Received 16 November 2012; 1st Revised 11 January 2013; 2nd Revised 20 February 2013; 3rd Revised 9 March 2013; Accepted 20 April 2013)

Copyright $(\subset$ The Society of Fashion and Textile Industry. 2013. This is an open access article distributed under the terms and conditions of the Creative Commons Attribution Non-Commercial license (http://creativecommons.org/licenses/by-nc/3.0/), which permits unrestricted non-commercial use, distribution, and reproduction in any medium, provided the original work is properly cited. 